\title{
The Production of Knowledge in Canada: Consolidation and Diversification
}

\author{
B. Godin, C. Doré and V. Larivière \\ INRS/OST \\ 3465, rue Durocher \\ Montreal (QUE) \\ Canada \\ $\mathrm{H} 2 \mathrm{X} 2 \mathrm{C} 6$
}

\begin{abstract}
The Canadian innovation system is composed of four main sectors: university, hospital, government, and industry. This paper analyzes each sector's strengths and weaknesses in terms of its scientific production. It is shown that Canadian science is increasingly produced in international collaboration and that all sectors are collaborating increasingly with each other.
\end{abstract}




\title{
The Production of Knowledge in Canada: \\ Consolidation and Diversification
}

\author{
B. Godin, C. Doré and V. Larivière \\ INRS/OST \\ 3465, rue Durocher \\ Montreal (QUE) \\ Canada \\ H2X 2C6
}

\section{Introduction}

During the last fifteen years, the Canadian Government has implemented a major change in the orientation of its science and technology (S\&T) policies. Federal strategies have in fact manifested enormous interest in oriented research, especially since 1987, when the Conservative Government unveiled a new S\&T policy that clearly focused on the needs of industry (Government of Canada, 1987). Now considered as having been the first policy document explicitly devoted to S\&T, the 1987 strategy put forward the following three initiatives: 1) the prioritization of emerging technologies; 2) elaboration of a new counterpart linking research council funding to the performance of projects co-financed by industry; and 3) progressive disengagement of the government in intramural research activities in favour of industry and universities.

Subsequent to the Conservative's Government S\&T policy, the Liberal Government launched a national consultation in 1994 that led to a new S\&T policy in 1996 (Government of Canada, 1996). That policy document contained nothing genuinely new since the objectives of the former policy were essentially the same: to advance knowledge; to increase the number of highly 
qualified personnel; and to continue supporting federal mandates (health, security, environment, etc.) and economic development. What emerged from these policies, both the Conservative and the Liberal, was a privileging of economics, mainly industrial innovation, jobs and wealth creation.

This orientation continues to this day. In 2002, for example, the Federal Government published an innovation strategy that was entirely focused on economic issues, including the need to develop human resources and skills for making Canada a world leader in science and technology (Government of Canada, 2002). The strategy set a series of important targets to be achieved by 2010, among them:

- rank among the top five countries in terms of R\&D performance, - double the Government of Canada's current investments in R\&D, - rank among world leaders in new innovations, - double the number of research personnel in our current labor force.

As a major source of research and ideas in Canada, universities have been called upon in every policy to be more oriented and, above all, more focused on social and industrial needs. For instance, research councils, which fund most of the academic research in Canada, were asked to develop programs aimed at increasing university-industry collaborations. Godin and Trépanier (2000) showed how the Councils' strategic plans responded to the new political demands. Their analysis clearly identified changes in the definition of Council problems, missions and objectives, which featured buzzwords like "strategic research", "university-industry collaboration" and "optimization" of university research. 
In many respects, these new S\&T policy trends support both the idea of national systems of innovation (NSI) composed of multiple actors in constant interaction (Lundvall, 1992; Nelson, 1993) and the hypothesis of an emerging new system of knowledge production, characterized by greater heterogeneity in scientific research and a growing affiliation of university researchers with extra-university partners. Knowledge would no longer be produced only in university settings, but also increasingly in many different loci, like hospitals, industries, and government laboratories, with a stronger orientation towards oriented research. In this system, so argue Gibbons et al., "the universities, in particular, will comprise only a part, perhaps only a small part, of the knowledge producing sector" (Gibbons et al., 1994, p. 85). Gibbons et al. call this system Mode 2, in contrast to Mode 1 where problems are addressed within a more academic setting.

Our purpose here is to quantitatively analyze the Canadian S\&T system in terms of the four major interrelated sectors that define an NSI: university, hospital, government and industry. Using bibliometric data on Canadian scientific publications, we analyze the interrelations between these sectors and show that universities have remained a dominant force in collaborative research despite recent policies and discourses prophesying their decline.

This paper reviews and updates recent works by the Canadian OST (Observatoire des sciences et des technologies). Section 2 presents the study's data and methodology. Section 3 situates Canada's scientific production with respect to the rest of the world. Section 4 analyzes the internationalization of Canadian research and section 5 discusses the diversification of this research. The last section assesses the impact of collaboration on university research. 


\section{Methodology}

The data were compiled from the Canadian Bibliometric Database produced by the Observatoire des sciences et des technologies (OST). The database covers the years 1980 to 1998 and was constructed using the CD-ROM editions of the Science Citation Index (SCI). All documents containing a Canadian address (hereafter called "Canadian papers" for the sake of brevity) were retained, cleaned for address harmonization and codified according to the sectors from which they originated. Although the SCI indexes 14 types of documents published in scientific journals, the present analysis is based on the three types that best reflect the production of new scientific knowledge: articles, reviews and notes. Together these items make up $80 \%$ of all the documents that appear in scientific journals surveyed by the SCI.

The documents were classified according to disciplines and specialties, using the classification system developed by Computer Horizon Inc. CHI's system, unlike the SCI's, never places a journal in more than one subject area, thus avoiding double counting. The classification includes eight major disciplinary fields, which are divided into more than one hundred specialties.

Since we are primarily interested in studying the relationships between sectors, we have attributed each paper to one or many of the following four sectors using the authors' institutional addresses: university, industry, government (federal and provincial) and hospital. A publication is assigned to each sector represented in the addresses. There is also an "other" category, which includes not-for-profit organizations, museums and college-level institutions. Though most 
hospitals are affiliated to universities, we found it useful to distinguish them from the latter when authors specified hospital addresses.

\section{Canada's Overall Scientific Production}

In 1998 , the United States was first in terms of scientific publications with $33,4 \%$, followed by Japan $(10,3 \%)$, Germany $(9,2 \%)$, the UK $(9,0 \%)$ and France $(6,8 \%)$. Canada ranked $6^{\text {th }}$ overall with a thin lead of $0,1 \%$ over Italy. In 1998, only 237 publications separated Canada's score from Italy's (see table 1). Preliminary results for 1999 show that Italy now surpasses Canada by nearly $2 \%$ in total publications. In fact, Italy increased the number of its yearly publications by more than $210 \%$ between 1980 and 1998 whereas Canada increased its yearly output by less than 58\%. During this period, the average annual growth in publications was almost $154 \%$ higher in Italy than in Canada $(6,6 \%$ versus $2,6 \%)$.

Nevertheless, Canadian scientific publications grew considerably between 1980 and 1998, increasing from approximately 16000 to 24770 . Canada's contribution to the scientific world increased steadily until 1992, then fell to 4,4\% by 1998 (see figure 1). With regard to research specialization, publications in clinical medicine $(31,5 \%)$, biomedical research (18\%) and biology $(11,6 \%)$ represented more than $61 \%$ of Canadian scientific production in 1998 . Then followed physics $(9,3 \%)$, chemistry $(9,1 \%)$, earth and space $(8,7 \%)$, engineering $(8,2 \%)$ and mathematics $(2,1 \%)$. 
Table 1

Scientific Publications by Country

\begin{tabular}{|c|c|c|c|c|c|}
\hline Country & 1980 & 1985 & 1990 & 1995 & 1998 \\
\hline United States & 131998 & 157224 & 172942 & 190068 & 189220 \\
\hline Percentage & $35,6 \%$ & $36,5 \%$ & $36,4 \%$ & $35,4 \%$ & $33,4 \%$ \\
\hline United Kingdom & 31524 & 37456 & 39826 & 48983 & 50956 \\
\hline Percentage & $8,5 \%$ & $8,7 \%$ & $8,4 \%$ & $9,1 \%$ & $9,0 \%$ \\
\hline Japan & 23991 & 32054 & 39995 & 50524 & 58171 \\
\hline Percentage & $6,5 \%$ & $7,4 \%$ & $8,4 \%$ & $9,4 \%$ & $10,3 \%$ \\
\hline Germany & 27808 & 31947 & 36129 & 44276 & 51987 \\
\hline Percentage & $7,5 \%$ & $7,4 \%$ & $7,6 \%$ & $8,3 \%$ & $9,2 \%$ \\
\hline France & 20205 & 21896 & 25668 & 34401 & 38469 \\
\hline Percentage & $5,5 \%$ & $5,1 \%$ & $5,4 \%$ & $6,4 \%$ & $6,8 \%$ \\
\hline Canada & 15707 & 19772 & 22701 & 25619 & 24770 \\
\hline Percentage & $4,2 \%$ & $4,6 \%$ & $4,8 \%$ & $4,8 \%$ & $4,4 \%$ \\
\hline Italy & 7880 & 11366 & 14800 & 21404 & 24533 \\
\hline Percentage & $2,1 \%$ & $2,6 \%$ & $3,1 \%$ & $4,0 \%$ & $4,3 \%$ \\
\hline Australia & 8215 & 9542 & 10573 & 13836 & 15494 \\
\hline Percentage & $2,2 \%$ & $2,2 \%$ & $2,2 \%$ & $2,6 \%$ & $2,7 \%$ \\
\hline Netherlands & 6050 & 8496 & 10850 & 14014 & 14978 \\
\hline Percentage & $1,6 \%$ & $2,0 \%$ & $2,3 \%$ & $2,6 \%$ & $2,6 \%$ \\
\hline India & 11680 & 10398 & 9446 & 9976 & 10825 \\
\hline Percentage & $3,2 \%$ & $2,4 \%$ & $2,0 \%$ & $1,9 \%$ & $1,9 \%$ \\
\hline Sweden & 6143 & 8108 & 9135 & 11273 & 12219 \\
\hline Percentage & $1,7 \%$ & $1,9 \%$ & $1,9 \%$ & $2,1 \%$ & $2,2 \%$ \\
\hline Russia & n.a. & n.a. & 282 & 21288 & 20607 \\
\hline Percentage & & & $0,1 \%$ & $4,0 \%$ & $3,6 \%$ \\
\hline $\mathbf{N}$ (number of papers) & 370419 & 430858 & 474647 & 536396 & 566394 \\
\hline
\end{tabular}

We calculated a "specialization index" for comparing the level of Canada's research activities with the rest of the World. This index indicates whether an institution or (in the present case) a country is more or less "specialized" (that is active) in a particular field in comparison to other countries. An index above 1,0 indicates that Canada produces a larger share of its publications in a given discipline than do other countries in general. Thus, in 1998, Canada was more specialized than the rest of the world in earth and space $(1,6)$ and biology $(1,5)$, about equal in biomedical research $(1,1)$ and mathematics $(1,1)$, and far less specialized in physics $(0,6)$ and chemistry $(0,7)$. 


\section{Figure 1}

\section{Canada's Share of the World's Scientific Publications 1980-1998}

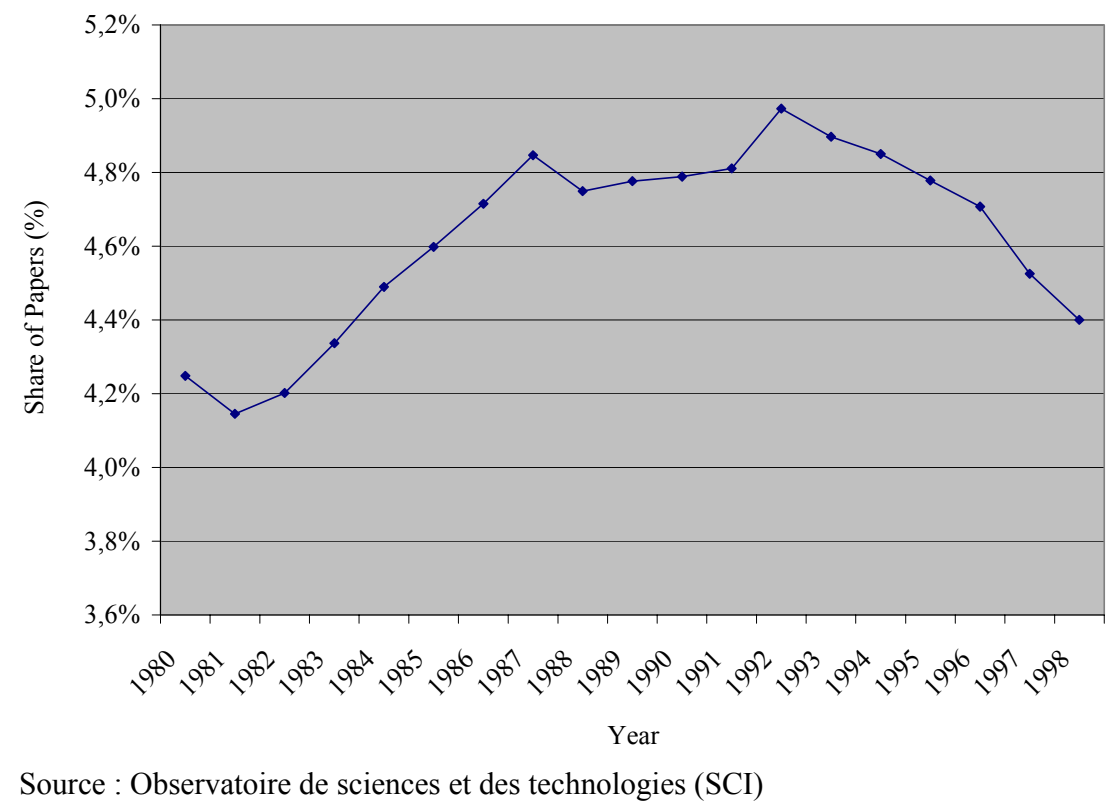

Overall, despite an important increase in absolute numbers, Canada's share of the world's scientific publications has not significantly improved since 1980. Canada's situation is not unique, however. Most industrialized countries have experienced a similar stagnation in the growth rate of their publications since the mid 1990's. The main hypothesis for explaining this trend is that given the leveling-off of financial resources devoted to $R \& D$, these countries have now reached their cruising speed in terms of scientific production. Over a fifteen-year period, they sustained a high rate of scientific production that permitted some of them to close scientific gaps and to adjust to new scientific and structural changes. Recent data now suggest that this trend has shifted to less industrialized countries. Many of them, like Taiwan, South Korea and China have multiplied their publications by more than a factor of 100 since 1990. 
Despite the plateau reached in Canadian scientific production, there is one thing that has been growing however: research in Canada is becoming increasingly collaborative. The next sections turn to the analysis of this phenomenon.

\section{Internationalization of Research}

A major point of interest is the growing proportion of Canada's scientific production that is realized with foreign researchers (Gingras, Godin and Foisy, 1999). The internationalization of Canadian publications has increased steadily from $15,5 \%$ in 1980 to $36,0 \%$ in 1998 . During this period, Canada's international collaborations are highest in Physics $(52,4 \%$ of the publications in this field) and mathematics (51,9\%), which have traditionally been well ahead of other fields. Then follow earth and space (46\%), biomedical research $(39,2 \%)$, engineering $(30,9 \%)$, chemistry $(30,3 \%)$ and biology $(26,7 \%)$.

Canadian collaborations with foreign countries are mostly realized with the USA $(52,7 \%)$, the United Kingdom (10,8\%), France $(9,9 \%)$ and Germany $(8,2 \%)$. These data confirm the hypothesis that "small" countries are publishing increasingly collaborative research, and especially with larger countries. Three factors explain these patterns of collaboration: geographical proximity (USA), history (colonial ties with the United Kingdom), and language (France) (Frame and Carpenter, 1979; Luukkonen, Persson and Silvertzen, 1992).

Notwithstanding the importance of the four major international collaborators in Canadian research, it seems obvious from figure 2 that internationalization in Canadian research has undergone a new trend since the end of the 1980's: a considerable increase in its collaborations 
with countries other than the USA. Major European countries are not bridging the gap but Italy, the Netherlands, Switzerland and Japan have increased their collaboration with Canada by more than $180 \%$ during the $1988-1998$ period.

Figure 2

Evolution of Canadian International Collaboration, 1980-1998

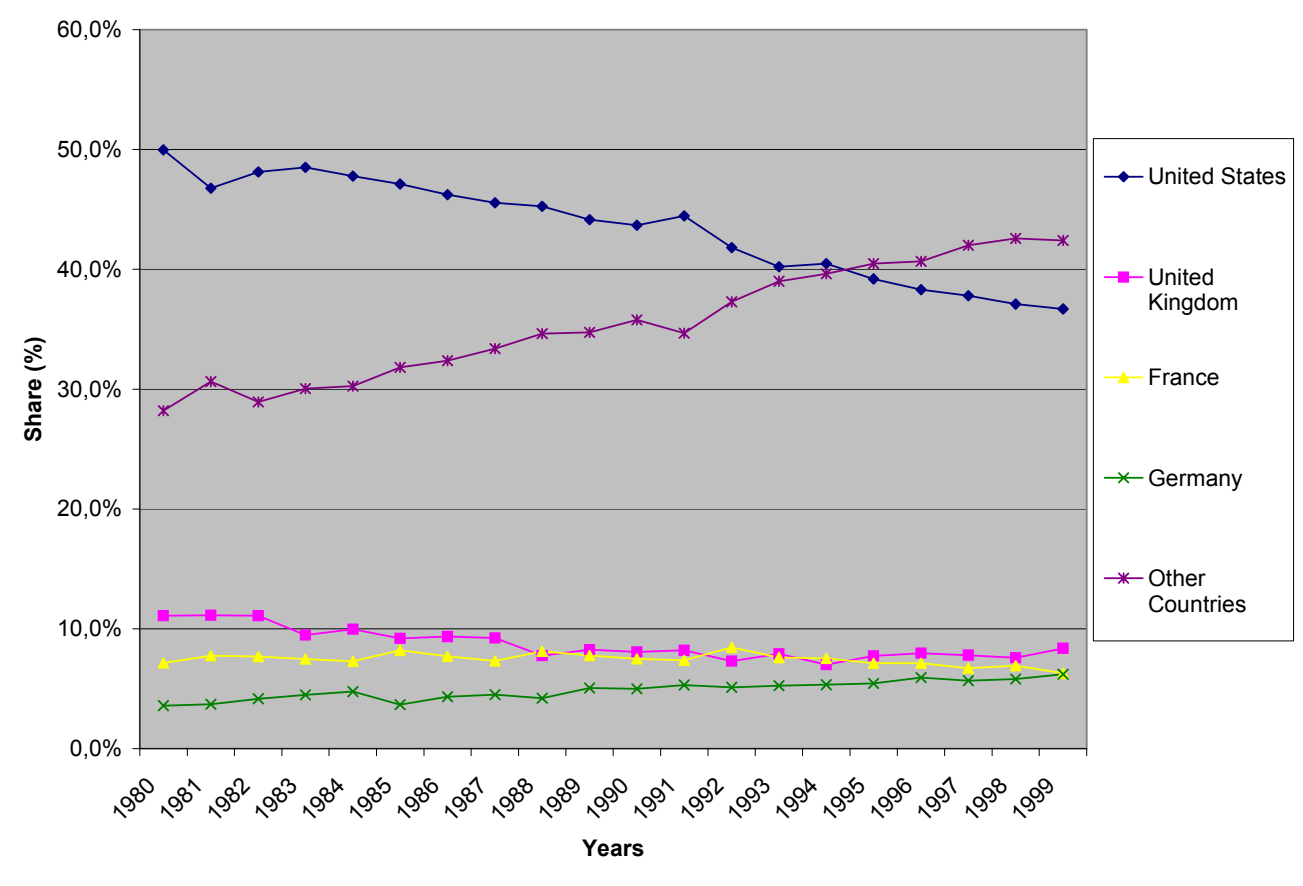

Source : Observatoire des sciences et des technologies (SCI)

\section{Diversification of Research}

In 1998 , the university sector was present in $84,0 \%$ of the 24,770 papers containing at least one Canadian address. The hospital sector was present in $14,4 \%$ of these papers, followed by the federal government $(11,5 \%)$, industry $(6,3 \%)$ and provincial government $(2,6 \%)$ sectors. 
For the period 1980-1998, the presence of sectors other than universities increased slightly from $37,1 \%$ to $39,3 \%$ of the total number of Canadian papers. This corresponds to a $66,9 \%$ growth in the absolute number of papers containing a non-university address, compared to $57,7 \%$ for the total number of Canadian papers. The fastest growing sector was industry with $92,1 \%$, followed by the hospital $(80,1 \%)$ sector. The growth of the federal government sector $(24,2 \%)$ was much less important during this period than that of the provincial government sector $(68,2 \%)$.

Research has therefore diversified over the period, but given this diversification, two things can happen if the growth comes from non-university research (Godin and Gingras, 2000b): 1) if the research was conducted independently of the university sector, we would expect to find a decline in the proportion of university papers as predicted by Gibbons et al.; or 2) if it was on the other hand conducted in collaboration with the university sector, we would expect to find that the proportion of university papers would not decline and that it would vary as a function of the level of collaboration between sectors. As we shall presently see, it is the second possibility that corresponds more closely to reality.

\section{The Growth of University Research}

Table 2 shows that the presence of the university sector in scientific papers increased from $75,5 \%$ in 1980 to $84,0 \%$ in 1998 (recall that this indicator is based on the presence of at least one university address in a paper and is computed on the total number of papers). The data thus clearly suggest that the real effect of diversification has been to further stimulate university research through collaboration rather than to diminish its presence in the system of research. An examination of the evolution of intersectorial collaborations will confirm this analysis. 
Table 2

Canadian Papers by Sector

\begin{tabular}{lrrrrr}
\hline Sector & $\mathbf{1 9 8 0}$ & $\mathbf{1 9 8 5}$ & $\mathbf{1 9 9 0}$ & $\mathbf{1 9 9 5}$ & $\mathbf{1 9 9 8}$ \\
\hline University & 11858 & 15251 & 18269 & 21203 & 20806 \\
Percentage & $75,5 \%$ & $77,1 \%$ & $80,5 \%$ & $82,8 \%$ & $84,0 \%$ \\
Hospital & 1978 & 2561 & 2955 & 3544 & 3562 \\
Percentage & $12,6 \%$ & $13,0 \%$ & $13,0 \%$ & $13,8 \%$ & $14,4 \%$ \\
Federal Gvt & 2291 & 2774 & 3080 & 3140 & 2845 \\
Percentage & $14,6 \%$ & $14,0 \%$ & $13,6 \%$ & $12,3 \%$ & $11,5 \%$ \\
Industry & 814 & 1170 & 1220 & 1530 & 1564 \\
Percentage & $5,2 \%$ & $5,9 \%$ & $5,4 \%$ & $6,0 \%$ & $6,3 \%$ \\
Provincial Gvt & 390 & 495 & 629 & 674 & 656 \\
Percentage & $2,5 \%$ & $2,5 \%$ & $2,8 \%$ & $2,6 \%$ & $2,6 \%$ \\
Others & 226 & 351 & 429 & 612 & 518 \\
Percentage & $1,4 \%$ & $1,8 \%$ & $1,9 \%$ & $2,4 \%$ & $2,1 \%$ \\
Unknown & 130 & 144 & 186 & 300 & 581 \\
Percentage & $0,8 \%$ & $0,7 \%$ & $0,8 \%$ & $1,2 \%$ & $2,3 \%$ \\
\hline N (number of papers) & $\mathbf{1 5 7 0 7}$ & $\mathbf{1 9 7 7 2}$ & $\mathbf{2 2} \mathbf{7 0 1}$ & $\mathbf{2 5} \mathbf{6 1 9}$ & $\mathbf{2 4 7 7 0}$ \\
\hline Source : Observatoire des sciences et des technologies (SCI) & & &
\end{tabular}

$\underline{\text { Intersectorial Collaborations }}$

We measured institutional collaborations between sectors using the addresses of authors in cosigned papers. For example, the presence of at least one university address and of at least one private firm address is counted as one university-industry collaboration. Scientific collaborations of universities with industries, hospitals and government laboratories increased by $175 \%$ from 1980 to 1998. As shown in Table 3, intersectorial collaborations went from $14,6 \%$ of papers with at least one university address in 1980 to $22,1 \%$ in 1998. Among all Canadian university publications in $1998,11,5 \%$ were published in collaboration with the hospital sector, 5,3\% with the federal government and 3,5\% with industry. For the same year, more than half of all 
university collaborators were hospitals, followed by federal laboratories $(24,1 \%)$, industries $(16,1 \%)$ and provincial laboratories $(8,0 \%)$.

Table 3

Collaboration of Universities with other Sectors

\begin{tabular}{lccccr}
\hline Sector & $\mathbf{1 9 8 0}$ & $\mathbf{1 9 8 5}$ & $\mathbf{1 9 9 0}$ & $\mathbf{1 9 9 5}$ & $\mathbf{1 9 9 8}$ \\
\hline Hospital & $8,6 \%$ & $9,7 \%$ & $9,8 \%$ & $11,0 \%$ & $11,5 \%$ \\
Federal government & $2,9 \%$ & $3,7 \%$ & $4,7 \%$ & $5,2 \%$ & $5,3 \%$ \\
Industry & $1,4 \%$ & $1,8 \%$ & $2,6 \%$ & $2,9 \%$ & $3,5 \%$ \\
Provincial Government & $1,2 \%$ & $1,3 \%$ & $1,6 \%$ & $1,6 \%$ & $1,8 \%$ \\
Others & $0,8 \%$ & $1,0 \%$ & $1,1 \%$ & $1,5 \%$ & $1,4 \%$ \\
Unknown & $0,4 \%$ & $0,2 \%$ & $0,3 \%$ & $0,1 \%$ & $0,8 \%$ \\
\hline Total (\%) & $\mathbf{1 4 , 6 \%}$ & $\mathbf{1 6 , 9 \%}$ & $\mathbf{1 8 , 9 \%}$ & $\mathbf{2 0 , 9 \%}$ & $\mathbf{2 2 , 1 \%}$ \\
\hline Source : Observatoire des sciences et des technologies (SCI) & & &
\end{tabular}

Source : Observatoire des sciences et des technologies (SCI)

University intersectorial collaborations of course vary according to discipline. In 1998, clinical medicine accounted for more than $45,9 \%$ of all university intersectorial collaborations. It was followed by Biomedical research $(19,0 \%)$, Biology $(11,4 \%)$, Earth and Space $(7,7 \%)$, Engineering and Technology (6,2\%), Physics (4,3\%), Chemistry $(3,4 \%)$ and Mathematics $(0,3 \%)$.

When we consider collaborations from the point of view of the other sectors, we find that in $1980,31,0 \%$ of their papers were written with universities, whereas in 1998, that proportion went up to $53,5 \%$. As shown in Table 4, the proportion of papers written in collaboration with universities has grown steadily over the period. Two sectors, the federal government and industry, even doubled their collaborations with universities during this period, thus strengthening their ties to them. The hospital sector, which already had a strong and stable relationship with universities, increased its collaborations to $67,1 \%$, while the provincial government sector published more than $55 \%$ of its papers in collaboration with universities. This 
trend confirms our thesis that the diversification of research activities outside universities is done within the university research system and thus contributes to its development rather than its decline.

Table 4

\section{Collaboration of Sectors with Universities}

\begin{tabular}{lccccc}
\hline Sector & $\mathbf{1 9 8 0}$ & $\mathbf{1 9 8 5}$ & $\mathbf{1 9 9 0}$ & $\mathbf{1 9 9 5}$ & $\mathbf{1 9 9 8}$ \\
\hline Hospital & $51,4 \%$ & $57,7 \%$ & $60,4 \%$ & $65,6 \%$ & $67,1 \%$ \\
Federal Government & $15,1 \%$ & $20,2 \%$ & $27,8 \%$ & $35,0 \%$ & $38,8 \%$ \\
Industry & $20,1 \%$ & $22,8 \%$ & $38,7 \%$ & $40,1 \%$ & $47,1 \%$ \\
Provincial Government & $36,7 \%$ & $39,0 \%$ & $47,9 \%$ & $49,0 \%$ & $55,6 \%$ \\
Others & $39,8 \%$ & $42,7 \%$ & $48,5 \%$ & $53,1 \%$ & $54,4 \%$ \\
Unknown & $32,3 \%$ & $25,7 \%$ & $26,9 \%$ & $9,7 \%$ & $29,8 \%$ \\
\hline Total (\%) & $\mathbf{3 1 , 0 \%}$ & $\mathbf{3 6 , 3 \%}$ & $\mathbf{4 3 , 7 \%}$ & $\mathbf{5 0 , 0 \%}$ & $\mathbf{5 3 , 5 \%}$ \\
\hline Source : Observatoire des sciences et des technologies (SCI)
\end{tabular}

\section{$\underline{\text { Federal Government Research in Specific Areas }}$}

Two sectors deserve particular mention. First, the federal government for the weight of its scientific production in several Canadian specialties. The federal government contributed to $11,5 \%$ of Canadian publications in 1998 , a drop of $3,1 \%$ from its level of $14,6 \%$ in 1980 . This sector remains very important in specific areas, however. In 1998, the federal government led Canadian publications in the following specialties (see Table 5): Oceanography and Limnology (50,8\% of all Canadians publications), Agriculture and Food science (47,4\%), Meteorology and Atmospheric sciences (46,7\%), Entomology (44,9\%), Environmental science (38,5\%), Dairy and Animal science (38,5\%) and Marine biology and Hydrobiology (37,7\%). 


\section{Table 5}

\section{Federal Share of Total Canadian Publications According to Specialty, 1980-1998}

\begin{tabular}{lrrr}
\hline Speciality & $\begin{array}{r}\text { Total Canadian } \\
\text { Publications }\end{array}$ & $\begin{array}{r}\text { N. Federal } \\
\text { Publications }\end{array}$ & $\begin{array}{r}\text { Federal \%of } \\
\text { Canadian Total }\end{array}$ \\
\hline Oceanography and Limnology & 2057 & 1045 & $50,8 \%$ \\
Agricult and Food science & 13371 & 6343 & $47,4 \%$ \\
Meteorology and Atmospheric science & 1919 & 897 & $46,7 \%$ \\
Entomology & 4251 & 1910 & $44,9 \%$ \\
Environmental science & 6786 & 2612 & $38,5 \%$ \\
Dairy and Animal science & 5055 & 1945 & $38,5 \%$ \\
Marine biology and Hydrobiology & 9079 & 3424 & $37,7 \%$ \\
Analytical chemistry & 5073 & 1600 & $31,5 \%$ \\
Botany & 14188 & 4311 & $30,4 \%$ \\
Astronomy and Astrophysics & 5385 & 1493 & $27,7 \%$ \\
Earth and Planetary science & 10418 & 2543 & $24,4 \%$ \\
Optics & 3014 & 715 & $23,7 \%$ \\
Geology & 6701 & 1446 & $21,6 \%$ \\
Acoustics & 1469 & 307 & $20,9 \%$ \\
\hline Total & $\mathbf{8 8 ~ 7 6 6}$ & $\mathbf{3 0 ~ 5 9 1}$ & $\mathbf{3 4 , 5 \%}$ \\
\hline Source: Observa
\end{tabular}

Source : Observatoire des sciences et des technologies (SCI)

In terms of the quality of the papers produced in the government's most active disciplines, existing data (Robitaille et Godin, 2002) shows that federal researchers have no cause to be envious of university research. Using the impact factor ${ }^{1}$ calculated by ISI as a measure of the quality of the research published by federal researchers, Robitaille and Godin demonstrated that although statistical differences exist between the federal government's scores and Canadian impact factors overall, they are minor. Except for very few specialties, the impact factors of federal publications are essentially on a par with those of Canadian publications. Papers coming out of federal laboratories are as good as academic papers, and are published in high impact journals.

\footnotetext{
${ }^{1}$ The impact factor is defined as the average number of citations received in a given year (here 1998) by articles published by a specific journal during the preceding two years. We assigned to each Canadian article the impact factor of the journal in which it was published. When the impact factor is over "1", the impact is considered to be superior to the reference average (Canada), and vice-versa.
} 


\section{The Rise of the Hospital Sector}

The second sector deserving mention is the hospital sector. The hospital sector has gained importance in Canadian science, outscoring the federal government's scientific production since 1995. The share of its publications in Canada represents more than $14 \%$ of the country's publications in 1998. That share varies among provinces, however. Figure 3 shows the share of papers attributed to the hospital sector for each of the following regions: the Atlantic Provinces, Ontario, Quebec and the Western Provinces - as well as for Canada as a whole. We see that for most provinces the hospital sector share increased between 1980 and 1998. In Ontario, this share reached $17 \%$ in 1998. The Atlantic and the Western Provinces are quite stable over the period, although we may observe a small increase in the Atlantic Provinces during the last few years.

Figure 3

The Share of Scientific Papers Assigned to Hospitals by Regions in Canada, 1980-1998

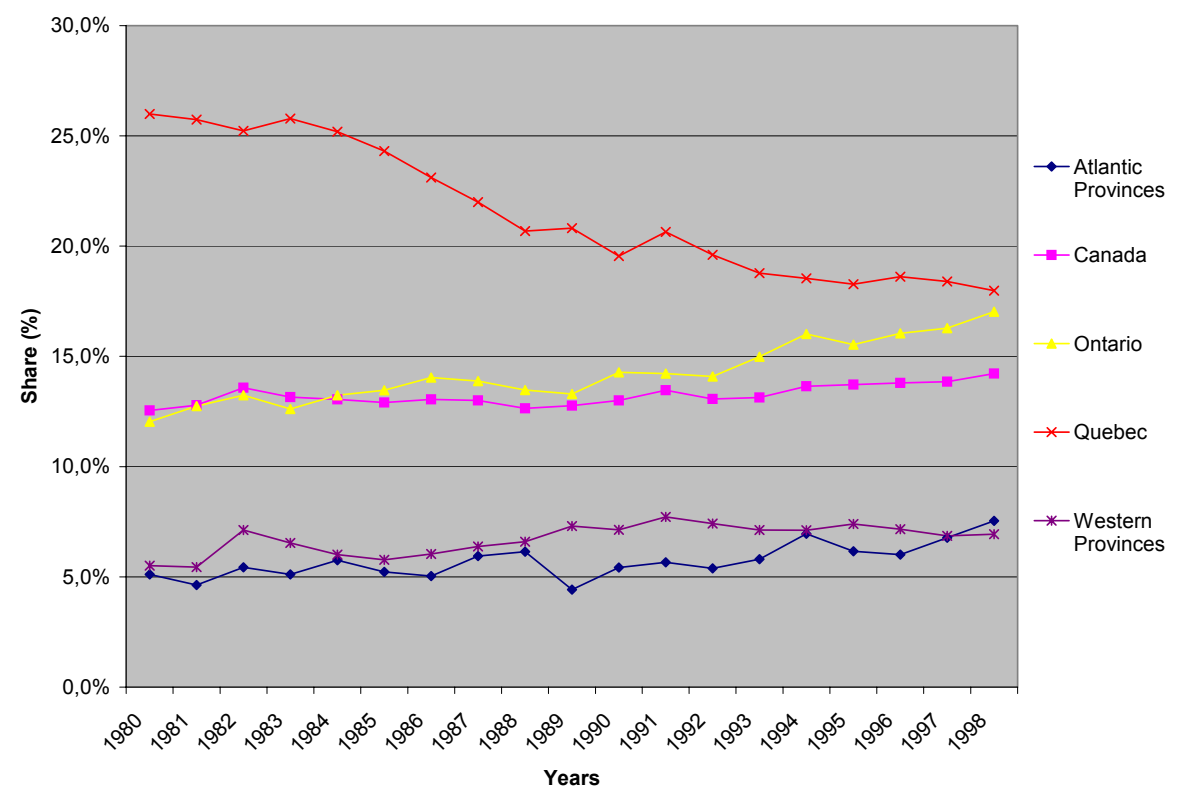

Source : Observatoire des sciences et des technologies (SCI) 
The Quebec hospital sector, however, clearly displays a distinct pattern: the share of its scientific output has steadily declined since 1980 . While this sector represented more than $26 \%$ of the province's scientific output in 1980 , it dropped to $18 \%$ by 1998 . There are two hypotheses that could explain the phenomenon: a genuine decline in the hospital sector's research effort, or a major change in the authoring practices of researchers - or both. The precise explanation awaits further research.

\section{The Impact of Collaboration on University Research}

Among the criticisms often raised against the collaboration of universities with industry and government laboratories, are that such partnerships would lead to more applied research and to research of lesser quality (Godin and Gingras, 2000a).

To test these assertions, we determined the level of "appliedness" of the research using a classification scheme constructed by $\mathrm{CHI}$ inc., which produces statistics for the National Science Foundation (NSF). Journals are classified by experts according to the degree to which they contain applied or basic research. The scale runs from 1 (very applied) to 4 (very fundamental).

Table 6 clearly shows that research undertaken in collaboration is more applied than research undertaken solely between university researchers, and this conclusion applies to all disciplines. One should also note that the average level of application is not significantly different when publications include international partners. Though this should come as no surprise, the data 
therefore confirm the hypothesis that university research done in intersectorial collaboration tends to be more applied.

Table 6

Average Appliedness of University Papers

\begin{tabular}{lrrrrr}
\hline & $\mathbf{1 9 8 0}$ & $\mathbf{1 9 8 5}$ & $\mathbf{1 9 9 0}$ & $\mathbf{1 9 9 5}$ & $\mathbf{1 9 9 8}$ \\
\hline All articles & $\mathbf{3 , 1}$ & $\mathbf{3 , 1}$ & $\mathbf{3 , 1}$ & $\mathbf{3 , 0}$ & $\mathbf{3 , 0}$ \\
National collaboration & 3,0 & 3,0 & 3,0 & 3,0 & 2,9 \\
$\quad$ with sectors & 2,3 & 2,5 & 2,6 & 2,6 & 2,6 \\
$\quad$ without sectors & 3,2 & 3,2 & 3,1 & 3,1 & 3,1 \\
International collaboration & 3,2 & 3,2 & 3,2 & 3,2 & 3,2 \\
$\quad$ with sectors & 2,6 & 2,9 & 2,9 & 2,9 & 2,9 \\
$\quad$ without sectors & 3,3 & 3,3 & 3,3 & 3,2 & 3,2 \\
\hline Source : Observatoire des sciences et des technologies & & &
\end{tabular}

We used the impact factor to test the hypothesis concerning the quality of intersectorial publications. Table 7 shows that, contrary to expectations, the average impact factor of intersectorial collaborative research is not different from that of university research at the national level (although significantly higher when international researchers co-signed, especially in biology, clinical medicine, physics, biomedical research and earth and space). On average, a paper issued from a research project realized by a university in collaboration with other sectors does not end up in a less visible journal than a paper authored only by university researchers.

Table 7

The Relative Weighted Impact Factor of University Papers

\begin{tabular}{lrrrrr}
\hline & $\mathbf{1 9 8 0}$ & $\mathbf{1 9 8 5}$ & $\mathbf{1 9 9 0}$ & $\mathbf{1 9 9 5}$ & $\mathbf{1 9 9 8}$ \\
\hline All articles & $\mathbf{1 , 0}$ & $\mathbf{1 , 0}$ & $\mathbf{1 , 0}$ & $\mathbf{1 , 0}$ & $\mathbf{1 , 0}$ \\
National collaboration & 1,0 & 1,0 & 1,0 & 1,0 & 1,0 \\
$\quad 1,0$ & 1,0 & 1,0 & 1,0 & 1,0 \\
with sectors & 1,0 & 1,0 & 1,0 & 1,0 & 1,0 \\
$\quad$ without sectors & 1,1 & 1,1 & 1,1 & 1,1 & 1,1 \\
International collaboration & 1,0 & 1,2 & 1,3 & 1,2 & 1,3 \\
$\quad$ with sectors & 1,1 & 1,1 & 1,1 & 1,1 & 1,1 \\
$\quad$ without sectors & \multicolumn{7}{c}{}
\end{tabular}


What about the impact of university-industry collaboration in particular? The increase in university collaboration seems to be of particular benefit to industrial research. As Table 3 shows, collaborative publications between university and industry have increased from $1,4 \%$ in 1980 to $3,5 \%$ of the total number of university publications in 1998 . At the same time, total industry publications have grown by nearly $92 \%$.

Most interesting is the growing impact of industrial publications done in collaboration with universities. Table 8 shows that the average impact factor of university-industry collaborations is nearly equal to the average impact factor of university publications: 0,99 versus 1,0 . Otherwise, the table shows an important increase of impact in the biomedical sciences from 1980 to 1998 $(30 \%)$

Table 8

The Relative Weighted Impact Factor of University-Industry Collaboration

\begin{tabular}{lccccc}
\hline Field & $\mathbf{1 9 8 0}$ & $\mathbf{1 9 8 5}$ & $\mathbf{1 9 9 0}$ & $\mathbf{1 9 9 5}$ & $\mathbf{1 9 9 8}$ \\
\hline Biology & 0,85 & 0,82 & 0,84 & 1,04 & 0,98 \\
Biomedical Research & 0,91 & 1,00 & 0,70 & 0,95 & 1,18 \\
Chemistry & 0,90 & 0,92 & 1,01 & 0,80 & 1,01 \\
Clinical Medicine & 0,84 & 1,19 & 0,83 & 1,06 & 0,98 \\
Earth and Space & 0,78 & 0,86 & 0,85 & 0,78 & 0,82 \\
Engineering & 1,02 & 0,99 & 0,87 & 0,96 & 0,96 \\
Mathematics & 1,31 & 1,83 & & 0,80 & 0,83 \\
Physics & 0,97 & 1,06 & 1,15 & 0,92 & 0,96 \\
\hline Total & $\mathbf{0 , 9 4}$ & $\mathbf{1 , 0 0}$ & $\mathbf{0 , 9 1}$ & $\mathbf{0 , 9 4}$ & $\mathbf{0 , 9 9}$ \\
\hline Source : Observatoire des sciences et des technologies (SCI) & &
\end{tabular}




\section{Conclusion}

Despite a real diversification of loci of production, the presence of universities in the production of scientific research has not diminished over time. This is essentially because new actors in the system of scientific production produce a large proportion of their knowledge in collaboration with universities.

Over a period of 18 years, the industry and federal government sectors have doubled their collaborations with universities, while provincial governments have increased such collaborations by more than 50\%, thereby increasing their links with institutions of higher education. Universities are thus more than ever at the heart of the Canada's innovation system. Figure 4 shows the level at which various sectors collaborated with universities for the year 1998.

Figure 4

Percentages of Collaboration of the Different Sectors with Universities (1998).

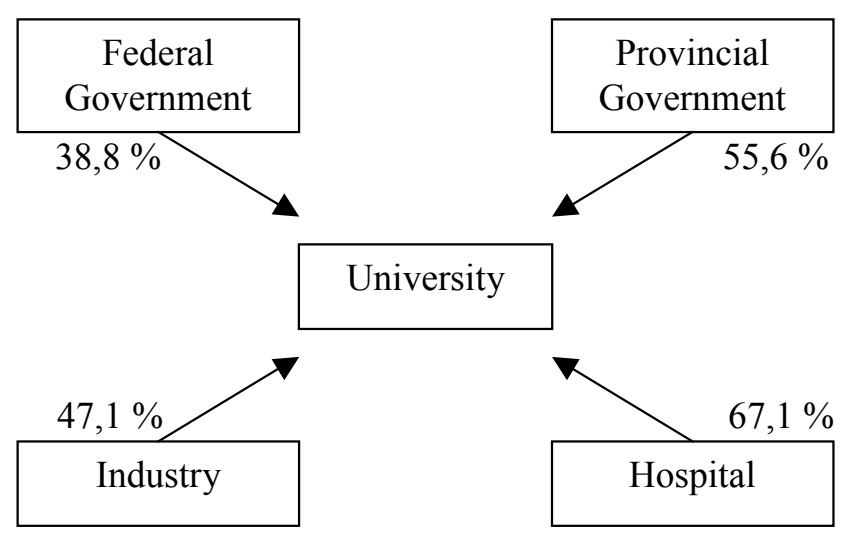


In the past two decades, governments have emphasized the need for stronger ties between universities and the rest of society, especially business. Policies have consequently promoted University-Industry relationships, and developed strategic programs devoted to oriented research. These programs and policies, which include economic incentives, certainly account for a large part of the trend toward stronger links between universities, industries and government laboratories (Gingras, Godin, Trépanier, 1999).

However, the steady growth of links between industry and universities is also consistent with recent studies suggesting that firms tend to draw upon universities for their R\&D programs because it saves them the cost of having to support their own research infrastructure (Slaughter and Leslie 1997). Big firms, even those with their own laboratories, as well as small and mediumsized companies, may therefore find it more expedient to collaborate with universities because it allows them to transfer part of their costs to the State, which is the main source of university funding.

Thus, far from receding into the margins of research, as suggested by Gibbons et al. (1994), universities have remained at the center of the knowledge production system through collaborative mechanisms. One could argue that our analysis is based on formal collaborations in journals that do not really reflect the tendency towards application-oriented research. But since we observe a growth of university-industry collaboration on this indicator, and since we know that other forms of collaboration (like financing) are also on the rise, we can confidently state that the data reflect a real trend (see Godin, 1998). Everything would therefore seem to suggest that the changing relationships between universities, industries and governments point towards 
stronger interactions between components of the knowledge production system rather than towards the marginalization of any one of the actors involved.

What are the policy implications of these results? On the one hand, they indicate that university researchers are certainly collaborating, and increasingly so, with extra-academic partners, as promoted by science and technology policies of Canada and other OECD Member countries. These policies therefore appear to have been highly effective in producing (some of) the observed changes. On the other hand, the results also indicate that the Canadian NSI cannot prosper without the contribution of its universities. Hence, the emphasis on industry and technology in recent science and technology policies should probably be balanced by an equal attention of and support towards universities and basic research. Governments must be careful not to make universities into the handmaidens of industry. Universities have so far preserved a certain level of autonomy in this respect, since only a fraction of the public funding that goes to Canadian universities is oriented towards industrial needs (Godin and Trépanier, 2000). Moreover, researchers are establishing links with industry on their own initiative, rather than on the basis of government rules that constrain them to do so. However, public discourses and government policies persist in claiming that more needs to be done to align universities to societal and industrial needs. As always, the danger lies in overstepping the boundary between sufficiency and excess. 


\section{REFERENCES}

Frame, J.D., and P. Carpenter (1979), International Research Collaboration, Social Studies of Science, 9: 481-497.

Gibbons, M., C. Limoges, H. Nowotny, S. Schwartzman, P. Scott, M. Trow (1994), The New Production of Knowledge: The Dynamics of Science and Research in Contemporary Societies, London: Sage.

Gingras, Y., B. Godin and M. Foisy (1999), The Internationalization of University Research in Canada, in S.L. Bond and J.-P. Lemasson, A New World of Knowledge: Canadian Universities and Globalization, Ottawa: IDRC: 77-98.

Gingras, Y., B. Godin, and M. Trépanier (1999), La place des universités dans les politiques scientifiques et technologiques canadiennes et québécoises, in P. Beaulieu and D. Bertrand, L'État québécois et les universités : acteurs et enjeux, Sainte-Foy: Presses de l'université du Québec : 69-99.

Godin, B. (1998), Writing Performative History: The New New Atlantis?, Social Studies of Science, 28 (3): 465-483.

Godin, B., and Y. Gingras (2000a), Impact of Collaborative Research on Academic Science, Science and Public Policy, 27 (1): 65-73.

Godin, B., and Y. Gingras (2000b), The Place of Universities in the System of Knowledge Production, Research Policy, 29 (2): 273-278.

Godin, B., and M. Trépanier (2000), Des organismes sous tension: les conseils subventionnaires et la politique scientifique, Sociologie et Société, 32 (1) : 17-42.

Government of Canada (2002), Achieving Excellence: Investing in People, Knowledge and Opportunity, Ottawa.

Government of Canada (1996), La stratégie fédérale en matière de sciences et de technologie, Ottawa.

Government of Canada (1987), Politique nationale en matière de sciences et de technologie, Ottawa.

Lundvall, B.-A. (ed.) (1992), National Systems of Innovation: Towards a Theory of Innovation and Interactive Learning, London: Pinter.

Luukkonen, T., O. Persson, G. Silvertzen (1992), Understanding Patterns of International Scientific Collaboration, Science, Technology and Human Values, 17 (1): 101-126. 
Nelson, R.R. (1993), National Innovation Systems: A Comparative Analysis, Oxford: Oxford University Press.

Robitaille, J.-P. and B. Godin (2002), The Evaluation of Government's Scientific Output: A Bibliometric Profile of Canada, Science and Public Policy, 29 (1): 59-68.

S. Slaughter and L.L. Leslie (1997), Academic Capitalism: Politics, Policies and the Entrepreneurial University, Baltimore: John Hopkins University Press. 